\title{
An unsuspicious duodenal foreign body
}

A 56-year-old woman with Peutz-Jeghers syndrome, who underwent a laparoscopic right hemicolectomy for colon adenocarcinoma 19 months earlier, presented for elective single-balloon antegrade enteroscopy to remove a $25 \mathrm{~mm}$ jejunal polyp previously identified on video capsule endoscopy.

During duodenal intubation, a foreign body was found wedged into the wall of the second portion of the duodenum ( Fig. 1 a). An attempt to gently pull the foreign body with grasping forceps was not successful. An abdominal computed tomography scan showed a moderately radiopaque foreign body (suggesting a bone), $20 \mathrm{~mm}$ in size, perforating the wall of the second duodenal portion to the retroperitoneum, with no associated inflammation, fluid collections or free air in the peritoneum ( $\triangleright$ Fig. 2 ).

As the patient was asymptomatic, with normal vital signs and no systemic inflammation on blood tests, an elective upper endoscopy in the operating room with surgeon support was performed the

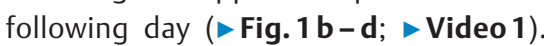
Through cap-assisted endoscopy, the foreign body was successfully retrieved using grasping forceps. Endoscopic review showed edematous duodenal mucosa with granulation tissue.

On close inspection, the foreign body was a plastic clip. On review of the patient's surgical notes, it was discovered that Hem-o-lok clips (Weck Closure Systems, Research Triangle Park, North Carolina, USA) had been used in the previous laparoscopic surgery for ileocolonic vessel ligation.

The Hem-o-lok clip is a nonabsorbable polymer locking clip that is used frequently during laparoscopic procedures. Despite their well known safety [1], a few
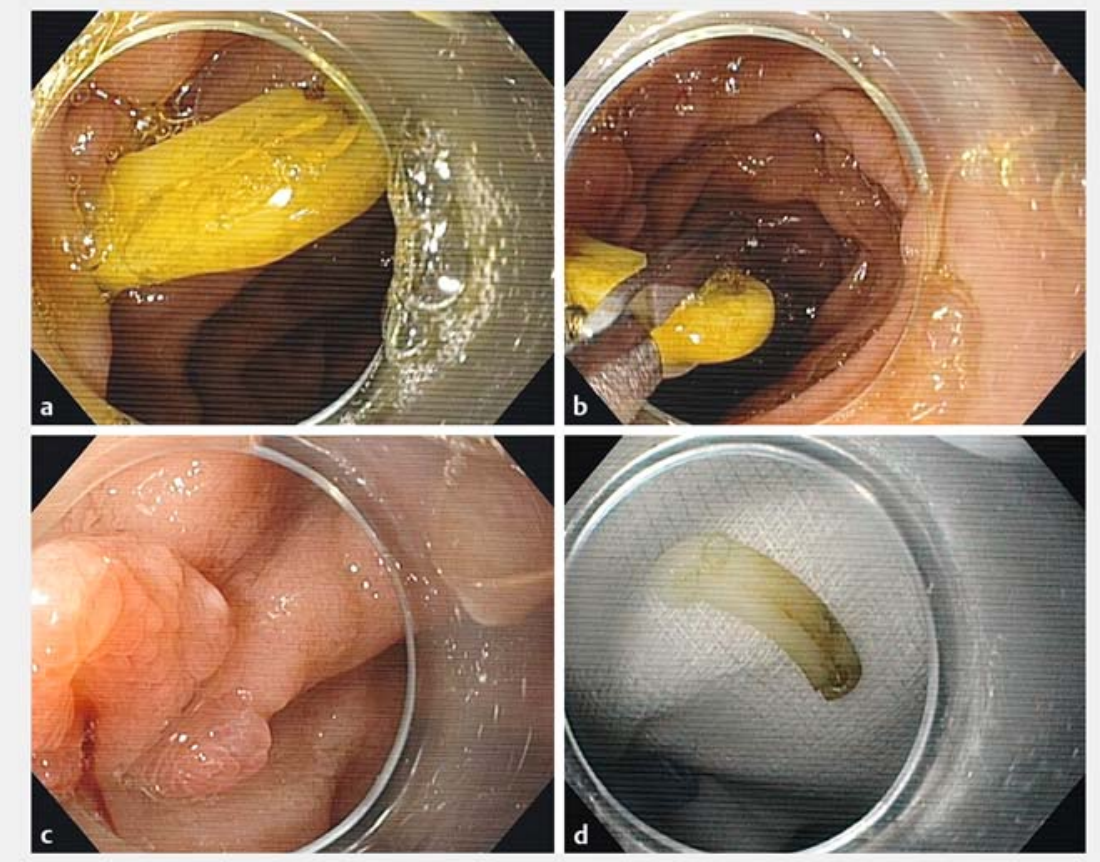

- Fig. 1 Foreign body removal-endoscopic view. a Foreign body wedged into the wall of the second portion of the duodenum. b Foreign body removal using grasping forceps. $\mathbf{c}$ Edematous duodenal mucosa at the site of the foreign body. $\mathbf{d}$ The foreign body was a Hem-o-Lok clip (Weck Closure Systems, Research Triangle Park, North Carolina, USA).

case reports of clip migration have been published [2-5]. The management of these cases remains controversial; both spontaneous detachment of these clips [3-5] and endoscopic removal [2] have been described.

In our case, the patient was asymptomatic and the clip was found on routine upper endoscopy. Hem-o-lok clip retrieval was possible using grasping forceps, without complications. The patient was discharged 2 days later with proton pump inhibitors.

Endoscopy_UCTN_Code_CCL_1AD_2AC

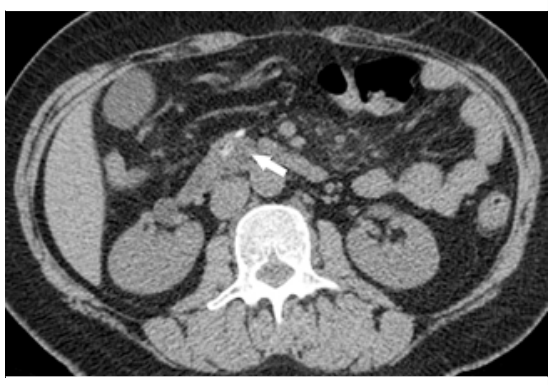

- Fig. 2 Abdominal computed tomography scan (axial view) showing a foreign body (arrow) located in the wall of the second duodenal portion. 


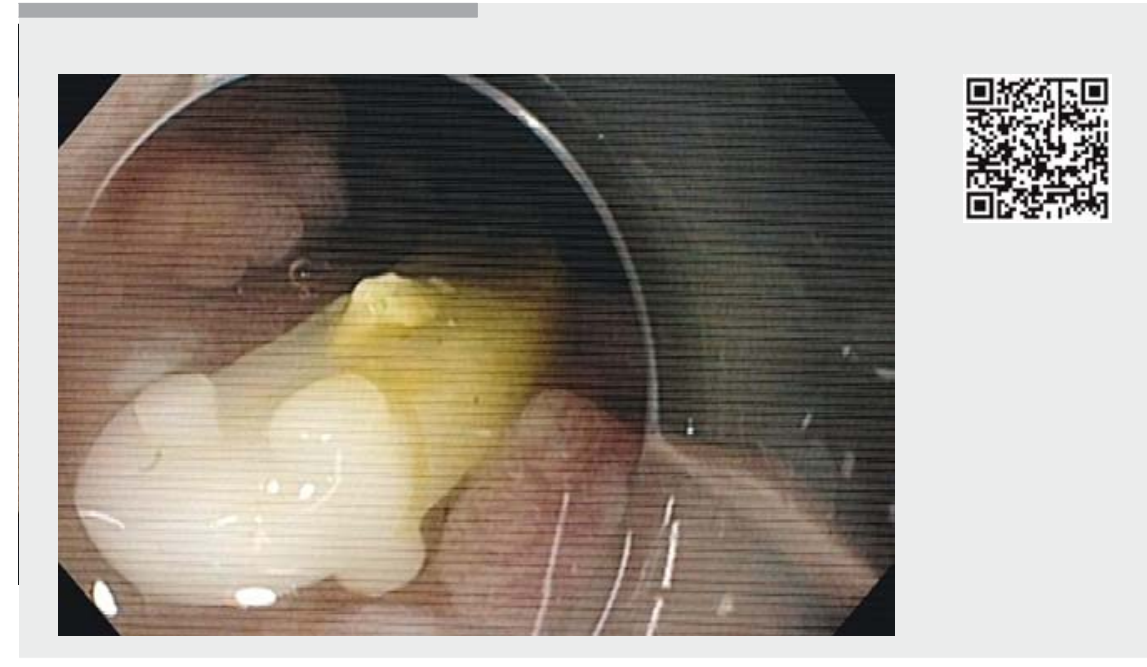

$\checkmark$ Video 1 Foreign body retrieval using grasping forceps.

\section{Competing interests}

None

The authors

\section{Mónica Garrido 1, ", Ricardo Marcos-}

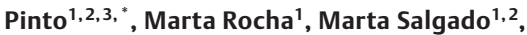
Anabela Rocha ${ }^{2,4}$, Isabel Pedroto ${ }^{1,2}$

1 Department of Gastroenterology, Porto University Hospital Center, Porto, Portugal

2 Institute of Biomedical Sciences of Abel Salazar (ICBAS), University of Porto, Porto, Portugal

3 Center for Research in Health Technologies and Information Systems (CINTESIS), Faculty of Medicine, University of Porto, Porto, Portugal

4 Department of Surgery, Porto University Hospital Center, Porto, Portugal

\footnotetext{
${ }^{*}$ These authors contributed equally to this work
}

[3] Soga K, Kassai K, Itani K. Duodenal ulcer induced by Hem-o-Lok clip after reduced port laparoscopic cholecystectomy. J Gastrointest Liver Dis 2016; 25: 95 - 98

[4] Park DJ, Kim BG, Jeong ID et al. Silent invasion of Hem-O-Lok clip. Ann Surg Treat Res 2018; 94: 159-161

[5] Mantoo SK, Rao J. An unusual cause of upper gastrointestinal bleeding. Endoscopy 2010; 42 (Suppl. 02): E123

\section{Bibliography}

DOI https://doi.org/10.1055/a-0665-4557

Published online: 14.8.2018

Endoscopy 2018; 50: E329-E330

(c) Georg Thieme Verlag KG

Stuttgart · New York

ISSN 0013-726X

\section{ENDOSCOPY E-VIDEOS \\ https://eref.thieme.de/e-videos}

Corresponding author

Mónica Garrido, MD

Gastroenterology Department, Centro Hospitalar e Universitário do Porto, Largo Prof. Abel Salazar, 4099-001 Porto, Portugal Fax: +351-22-2077500

monicasofiagarrido@gmail.com

\section{References}

[1] Aminian A, Khorgami Z. Hem-O-Lok clip is safe in minimally invasive general surgery: a single center experience and review of data from Food and Drug Administration. J Minim Invasive Surg Sci 2012; 1: 52 - 57

[2] Seyyedmajidi M, Hosseini SA, Hajiebrahimi S et al. Hem-o-Lok clip in the first part of duodenum after laparoscopic cholecystectomy. Case Rep Gastrointest Med 2013; 2013: 251634 